(100)

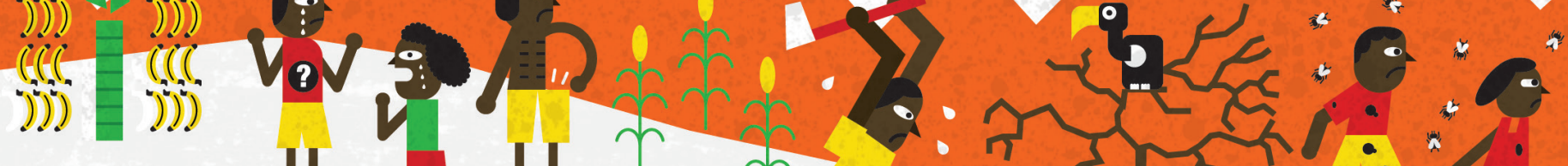

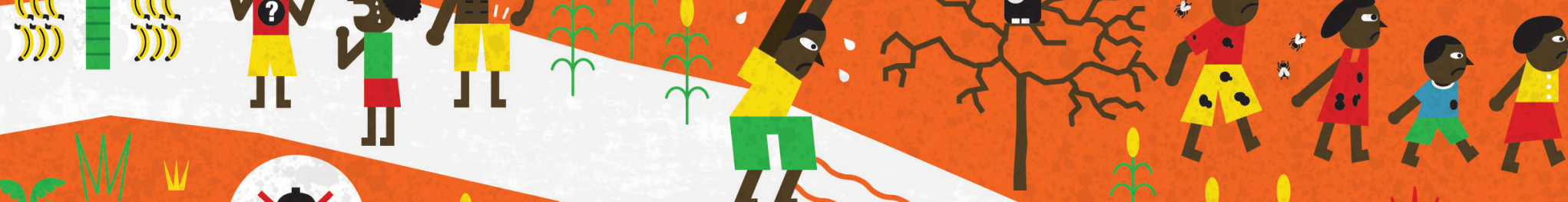

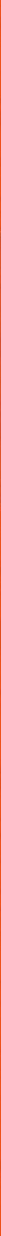

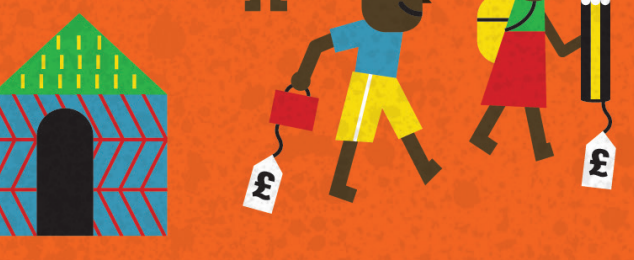




\section{Reducing poverty in the first 18 years of life: Burundi}

This illustration presents combined findings from a research project on monetary and multidimensional child poverty and the evaluation of Concern Worldwide's 'Terintambwe' programme in Burundi. It is based on information from survey data collected for the Concern programme evaluation in December 2013 and April 2015 and on discussions with 40 children and 91 adults in Cibitoke and Kirundo provinces from March to May 2015.

The Terintambwe programme was implemented over a period of two years to help the poorest households with cash transfers and training on how to set up income generating activities. Households also received health insurance cards for all members, more general training and home visits by case workers regarding hygienic practices, nutrition and gender equality and support in setting up kitchen gardens. This comprehensive package of support has the potential to improve both household wealth and child wellbeing. This research tries to understand how household wealth overlaps with child wellbeing and to what extent improvements in household wealth go hand-in-hand with improvements in child wellbeing.

\section{Household wealth and child wellbeing}

1. Before the Terintambwe programme, most children lived in households with little wealth and experienced poor wellbeing. Many children had poor diets, did not visit a clinic when sick, were unable to go to school or experienced poor hygiene.

2. Lack of household wealth strongly overlaps with bad child wellbeing but the two issues are not necessarily the same. In other words, there are children living in households with low wealth but who have good child wellbeing. By the same token, there are children living in households that are wealthy but that have bad child wellbeing. For example, parents in households with high income might have less time to spend with their children to help them with school or other issues.

\section{Impact of the Terintambwe programme}

3. The programme had a positive impact on household wealth and had large positive impacts on child wellbeing through increased numbers of meals, diet diversity, school attendance, shelter conditions and hygiene practices.

4. Training as well as coaching provided by case workers informed parents about how to spend increased income for the benefit of their children, created awareness about hygienic practices such as the importance of keeping the home and clothing clean, washing hands after toileting and before eating and the importance of seeking health care when a child is sick. The provision of the health insurance card facilitated parents act upon this awareness.

\section{Factors contributing to improvements in child wellbeing}

5. Improvements in household income and wealth help parents to increase the number of meals and diversity of foods that children eat, afford school fees and buy clothing for their children. The establishment of kitchen gardens for growing vegetables can contribute to greater dietary diversity for children and provision of school materials facilitates school attendance.

6. Training and coaching increases knowledge and awareness about practices to improve child wellbeing. Direct provision of school materials and health insurance cards facilitates access to basic services for children.

7. Lack of job opportunities discourages children from continuing their education even if that is possible and to look for work in the mining industry or by going to Rwanda. This lack of opportunities and declining agricultural productivity causes anxiety among parents regarding the future for their children. Wider structural changes and greater economic opportunities that offer prospects for future opportunities for children both in and outside of agriculture are crucial for improving child wellbeing at present.

This note was written by Keetie Roelen and edited by Vivienne Benson in November 2015. The author would like to acknowledge the invaluable support of Concern Worldwide, Biraturaba, Hannah Hudson and the parents and children interviewed for this research in the process of data collection and analysis. This research was funded by ESRC grant ES-K001833-1 and supported by Concern Worldwide.

The illustrations are copyright to Jorge Martin. 